\title{
Coadsorption of copper and perfluorooctane sulfonate onto multi-walled carbon nanotubes
}

\author{
Yanping Zhou ${ }^{a}$, Bei Wen ${ }^{\mathrm{a}, *}$, Zhiguo Pei ${ }^{\mathrm{a}}$, Guangcai Chen ${ }^{\mathrm{b}}$, Jitao Lv ${ }^{\mathrm{a}}$, Jing Fang ${ }^{\mathrm{c}}$, Xiaoquan Shan ${ }^{\mathrm{a}}$, \\ Shuzhen Zhang ${ }^{\mathrm{a}}$ \\ a State Key Laboratory of Environmental Chemistry and Ecotoxicology, Research Center for Eco-Environmental Sciences, Chinese Academy of Sciences, Beijing 100085, China \\ ${ }^{\mathrm{b}}$ Research Institute of Subtropical Forestry, Chinese Academy of Forestry, Fuyang, Zhejiang 311400, China \\ 'School of Environmental Science and Engineering, Zhejiang Gongshang University, Hangzhou 310012, China
}

\section{H I G H L I G H T S}

- Sorption and desorption of PFOS and Cu(II) on MWCNTs in single- and bi-solute systems were studied.

- Sorption capacities of PFOS and $\mathrm{Cu}(\mathrm{II})$ in bi-solute system were higher than those in single-solute system.

- Desorption behaviors of PFOS and $\mathrm{Cu}(\mathrm{II})$ in bi-solute system were different from those in single-solute system.

- $\mathrm{Cu}$ formed inner-sphere complexes without PFOS, while out-sphere complexes with PFOS.

\section{A R T I C L E I N F O}

\section{Article history:}

Received 22 March 2012

Received in revised form 8 June 2012

Accepted 11 June 2012

Available online 13 July 2012

\section{Keywords:}

Co-adsorption

Desorption

PFOS

$\mathrm{Cu}(\mathrm{II})$

MWCNTs

X-ray absorption spectroscopy

\begin{abstract}
A B S T R A C T
Multi-walled carbon nanotubes (MWCNTs) are superadsorbents for perfluorooctane sulfonate (PFOS) and heavy metals, which coexist in wastewater. The interaction between PFOS and $\mathrm{Cu}(\mathrm{II})$ with regard to their adsorption and desorption on MWCNTs was evaluated in this study. The adsorption of PFOS on MWCNTs enhanced with an increase of $\mathrm{Cu}(\mathrm{II})$. Desorption of PFOS showed no hysteresis without $\mathrm{Cu}(\mathrm{II})$, while pronounced hysteresis with $\mathrm{Cu}(\mathrm{II})$. Increases of the adsorption and the occurrence of desorption hysteresis of PFOS in the presence of $\mathrm{Cu}(\mathrm{II})$ may due to the PFOS adsorption via a $\mathrm{Cu}(\mathrm{II})$ bridge. The adsorption of $\mathrm{Cu}(\mathrm{II})$ increased with an increase of PFOS. The desorption hysteresis factors in the presence of PFOS were lower than those in the absence of PFOS. Increases of the adsorption and decreases of desorption hysteresis factors may be attributed to the $\mathrm{Cu}(\mathrm{II})$ adsorption via a PFOS bridge. Results obtained by X-ray absorption spectroscopy verified the formation of inner-sphere complexes between $\mathrm{Cu}(\mathrm{II})$ and functional groups of MWCNTs without PFOS, while out-sphere complexes with large amount of PFOS. The effect of $\mathrm{Cu}(\mathrm{II})$ and PFOS adsorption on the zeta potential of MWCNTs was also studied. The results showed that the coexistence of $\mathrm{Cu}(\mathrm{II})$ and PFOS greatly affects their sorption and desorption behaviors on MWCNTs thereby their fate and transport in wastewater.
\end{abstract}

(C) 2012 Elsevier B.V. All rights reserved.

\section{Introduction}

Perfluorooctane sulfonate (PFOS) is an anthropogenic organic chemical, which has been employed in industrial and commercial applications for over 40 years. It is the stable end product of the degradation of most perfluorooctanesulfonylfluoride (POSF)-based perfluorochemicals, and resistant to hydrolysis, photolysis, biodegradation and metabolism, thus persistent in the environment [1]. PFOS has been found in various environmental and biological

\footnotetext{
* Corresponding author. Tel.: +86 10 62923560; fax: +86 1062923563 .

E-mail address: bwen@rcees.ac.cn (B. Wen).
}

matrices [2], and is recognized as an emerging persistent organic pollutant.

Much attention has been paid on the source and exposure pathways of PFOS in the environment. Industrial and municipal wastewater has recently been identified as a significant source [3]. A few studies reported the occurrence of PFOS in the wastewater [3-6]. It was found that the concentration of PFOS in the wastewater treatment plant (WWTP) effluent was higher than that in the influent $[3,6]$. One of the reasons was the limitation of conventional biological treatments in removing PFOS from aqueous streams because of its biodegradation-resistant nature. It has been demonstrated in many cases that, adsorption is an economical method to remove pollutants from wastewater. The adsorption of PFOS onto non 
ion-exchange polymers [7], activated carbon [7,8], chitosan-based molecularly imprinted polymer adsorbents [9] and resins [8] were reported. Ion exchange, electrostatic and hydrophobic interactions were suggested to be involved in the sorption.

In addition to PFOS, high concentrations of heavy metal cations, such as $\mathrm{Cu}(\mathrm{II}), \mathrm{Zn}(\mathrm{II}), \mathrm{Co}(\mathrm{II}), \mathrm{Cd}(\mathrm{II})$ and $\mathrm{Pb}(\mathrm{II})$ are typically found in industrial and municipal sewage influents and effluents $[10,11]$. Heavy metal cations are reported to affect the sorption of ionizable organic contaminants [12]. However, little information is available about the impact of heavy metals on the adsorption of PFOS so far. Effect of alkaline-earth metal ions, such as $\mathrm{Ca}$ (II) on the adsorption of PFOS has been reported. Higgins and Luthy found that in the presence of $\mathrm{Ca}(\mathrm{II})$, the sorption of anionic PFOS on sediments increased significantly [13]. Similar observation of sorption capacity increases as a result of $\mathrm{Ca}$ (II) addition was reported for PFOS sorption on oil-derived black carbon [14] and minerals [15]. However, results obtained by Wang and Shih showed that the adsorption of PFOS on alumina decreased with an increase in $\mathrm{Ca}(\mathrm{II})$, due to the compression of the electrical double layers and formation of bridges between calcium ions and PFOS anions in solution [16].

Multi-walled carbon nanotubes (MWCNTs) have aroused widespread attention as a new type of adsorbents due to their outstanding ability for the removal of various organic and inorganic pollutants from large volumes of wastewater [17-21]. Adsorption and desorption of pollutants onto and from MWCNTs in aqueous phases is a critical process for environmental application of MWCNTs in water treatment [22-24]. This process is also important for determining the environmental and health impacts of both MWCNTs and pollutants [17,25-27]. In our previous work, $\mathrm{Cu}(\mathrm{II})$ were found to diminish the sorption of atrazine [28] and trichlorophenol [29] on MWCNTs, whereas atrazine or trichlorophenol had no influence on $\mathrm{Cu}$ (II) sorption. The mechanisms ascribed were the formation of surface or inner-sphere complexes of $\mathrm{Cu}(\mathrm{II})$ through carboxylic groups and hydration, which may occupy part of the surface of MWCNTs. Moreover, the large hydration shell of metal cations may intrude or shield the hydrophobic and hydrophilic sites and indirectly compete with atrazine or 2,4,6-trichlorophenol for surface sites, leading to the inhibition of their adsorption around the metal-complexed moieties.

Previous works have reported the sorption of heavy metal ions and PFOS on MWCNTs separately [30,31]. However, there are currently few studies on the dual effects of metals on the sorption of PFOS and conversely of PFOS on metal adsorption on MWCNTs. In this manuscript we focus on the dual effect between PFOS and $\mathrm{Cu}(\mathrm{II})$ on their sorption onto and desorption from MWCNTs. The interaction between PFOS and $\mathrm{Cu}(\mathrm{II})$ in solution was also discussed.

\section{Materials and methods}

\subsection{Chemicals}

Perfluorooctane-sulfonic potassium (PFOS, >98\%) was purchased from Sigma- Aldrich Chemical Co. and was used as-received. It has a water solubility of $570 \mathrm{mg} / \mathrm{L}$ [31] and density of $1.95 \mathrm{~g} / \mathrm{cm}^{3}$ (taken from the website by SPARC: http://ibmlc2.chem.uga.edu/ sparc). Stock solution of $\mathrm{Cu}$ (II) was prepared from copper nitrate. All chemicals are of analytical reagent grade or better.

\subsection{Adsorbents}

Pristine and oxidative multi-walled carbon nanotubes (referred as Pri-MWCNTs and O-MWCNTs) were purchased from Chengdu Organic Chemistry Co. Ltd., Chinese Academy of Sciences. According to the manufacturer, the MWCNTs were synthesized by CVD method and have a purity of $+95 \%$, length of $10-30 \mu \mathrm{m}$, outer diameter of $10-20 \mathrm{~nm}$, and inner diameter of 5-10 nm. The TEM images of Pri-MWCNTs and O-MWCNTs are shown in Fig. 1. Detail information about the surface oxygen-containing groups was reported in our previous work [28,29]. Nitrogen adsorption/desorption isotherms at $77 \mathrm{~K}$ and carbon-dioxide adsorption isotherms at $273 \mathrm{~K}$ of MWCNTs were obtained by using a Nova 4200e surface area and pore size analyzer (Quantachrome Instruments, USA). Specific surface areas (SSA) and mesopore volume $\left(V_{\text {mes }}\right)$ of MWCNTs were calculated from the isotherms using Brunauer-Emmett-Teller (BET), micropore volume $\left(V_{\text {mic }}\right)$ using DFT method. The oxygen content and surface functional groups on MWCNTs were determined by X-ray photoelectron spectroscopy (ESCALab220iXL electron spectrometer from VG Scientific, USA) using $300 \mathrm{~W}$ $\mathrm{Al} \mathrm{K} \alpha$ radiation under the base pressure about $3 \times 10^{-9}$ mbar and Boehm titration. Zero points of charge (ZPC) of MWCNTs were obtained by plotting zeta potentials, which were measured in triplicate with Malvern ZetaSizer Nano S90 (Malvern Instrument Ltd., UK), versus $\mathrm{pH}$.

\subsection{Sorption and desorption experiment}

A batch technique was utilized for the sorption of PFOS, or $\mathrm{Cu}(\mathrm{II})$, or cosorption of PFOS and $\mathrm{Cu}$ (II). $15 \mathrm{mg}$ of MWCNTs were combined with the test $25 \mathrm{~mL}$ of electrolyte solution $\left(0.01 \mathrm{M} \mathrm{NaNO}_{3}\right.$ and $0.1 \mathrm{~g} /$ $\mathrm{L} \mathrm{NaN}_{3}$, pH 5.5) containing different concentrations of PFOS (0.02$0.45 \mathrm{mmol} / \mathrm{L})$, or $\mathrm{Cu}$ (II) $(0.05-0.5 \mathrm{mmol} / \mathrm{L})$, or the mixture of PFOS and $\mathrm{Cu}(\mathrm{II})$ in $50-\mathrm{mL}$ polypropylene tubes. Reactors were mixed completely by shaking at $100 \mathrm{rpm}$ at $20 \pm 0.5^{\circ} \mathrm{C}$ for 2 day. The $\mathrm{pH}$ value of the background solution was monitored three times during the sorption processes at every $12 \mathrm{~h}$ intervals and adjusted to 5.5 for all isotherms by dropwise addition of $0.1 \mathrm{~mol} / \mathrm{L} \mathrm{HNO}_{3}$ or $0.1 \mathrm{~mol} / \mathrm{L}$ $\mathrm{NaOH}$ if necessary. The preliminary experimental results showed that the $\mathrm{pH}$ value of the equilibration suspensions remained unchanged during the adsorption process, and apparent equilibration was reached in 1 and $2 \mathrm{~d}$ for $\mathrm{Cu}(\mathrm{II})$ and PFOS respectively. After centrifugation at $5000 \mathrm{~g}$ for $20 \mathrm{~min}$, supernatants were withdrawn and final PFOS and Cu concentrations were determined.

PFOS desorption experiments were conducted using a sequential decant-refill technique immediately following the completion of sorption experiments. A portion of the supernatant $(10 \mathrm{~mL})$ was withdrawn using a pipet and immediately replaced by the same volume of fresh desorption solution $\left(0.01 \mathrm{~mol} / \mathrm{L} \mathrm{NaNO}_{3}+\right.$ $\left.0.1 \mathrm{~g} / \mathrm{LNaN}_{3}, \mathrm{pH} 5.5\right)$. As for the sorption experiments at the end of each desorption cycle ( $2 \mathrm{~d}$ ), the supernatant was sampled and determined. Desorption process was repeated for three compete cycles and as was done in the sorption experiments the solution $\mathrm{pH}$ during desorption processes was readjusted to $5.5 \pm 0.1$ three times at $12 \mathrm{~h}$ intervals.

Single point sorption experiments were performed at an initial concentration of $0.26 \mathrm{mmol} / \mathrm{L}$ PFOS, or $0.26 \mathrm{mmol} / \mathrm{L} \mathrm{Cu}(\mathrm{II})$ as nitrate. Single point sorption experiments were performed to test the effects of $\mathrm{Cu}$ (II) concentrations on the sorption of PFOS and conversely of PFOS concentrations on metal adsorption on MWCNTs.

Blank experiments indicated that MWCNTs contained no detectable levels of PFOS or $\mathrm{Cu}(\mathrm{II})$, and the losses caused by degradation, adsorption onto polypropylene tubes, removal and replacement operation were less than 3\%. Therefore, the amount of PFOS, $\mathrm{Cu}$ (II) adsorbed was directly calculated by mass differences between the initial and final concentrations.

\subsection{Analysis}

An ultra performance liquid chromatography-tandem mass spectrometry (UPLC-MS/MS) was used to determine the concentrations of PFOS, with an UPLC system (ACQUITY, Waters Corp., USA) equipped with a C18 column $(2.1 \times 150 \mathrm{~mm}, 5 \mu \mathrm{m}$, Waters Corp., 

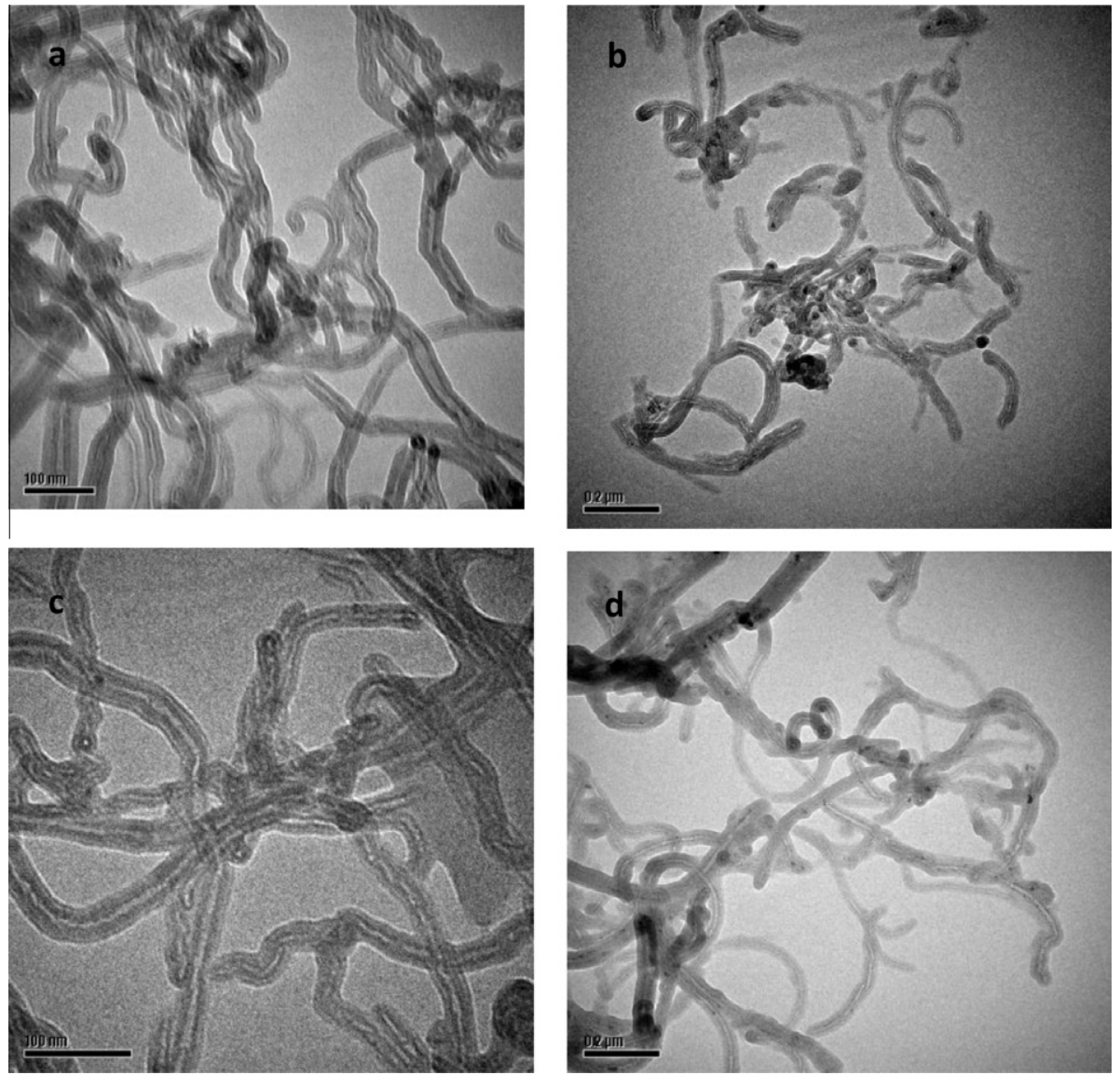

Fig. 1. TEM images of MWCNTs: (a and b) Pri-MWCNTs; (c and d) O-MWCNTs.

USA) and MS system Quattro Premier XE tandem quadrupole mass spectrometer (Waters Corp., USA) equipped with an electrospray ionization source. The mixture of acetonitrile $/ 10 \mathrm{mM}$ ammonium acetate $(\mathrm{v} / \mathrm{v}, 45 / 55)$ was used as the mobile phase at a flow rate of $0.2 \mathrm{~mL} / \mathrm{min}$. $\mathrm{Cu}$ (II) concentrations in the equilibrium solutions were determined by ICP-AES at 224.7 nm (Optima DV2000, PerkinElmer, USA).

\subsection{Determination of free copper ion $\left(\mathrm{Cu}^{2+}\right)$ concentrations in the presence of PFOS}

Copper ion selective electrodes (CU-ISE) in combination with a voltmeter of $0.1 \mathrm{mV}$ resolution (model 9629, Orion Research, Cambridge, MA) were used to measure $\mathrm{Cu}^{2+}$ concentrations in solutions containing $50 \mu \mathrm{mol} / \mathrm{L} \mathrm{Cu}(\mathrm{II})$ and different concentrations of PFOS. Solution containing $50 \mu \mathrm{mol} / \mathrm{L} \mathrm{Cu}$ (II) but no PFOS was used as control. The $\mathrm{Cu}$-ISE was activated in $0.5 \mathrm{~mol} / \mathrm{L} \mathrm{Cu}\left(\mathrm{NO}_{3}\right)_{2}$ for $2 \mathrm{~h}$ and rinsed with Milli-Q water before use. The limit of detection was $0.7 \mu \mathrm{mol} / \mathrm{L} \mathrm{Cu}^{2+}$. The activity of $\mathrm{Cu}^{2+}$ at each calibration point was calculated using the speciation program ChemEQL based on the total $\mathrm{Cu}$ concentration together with other parameters including $\mathrm{pH}$, alkalinity, and major ion concentrations constituting inputs to the model.

\subsection{Zeta potential ( $\xi$-potential) measurement}

The suspension for $\xi$-potential measurements was prepared by mixing MWCNTs (15 mg) with $0.01 \mathrm{M} \mathrm{NaNO}_{3}$ solution $(25 \mathrm{~mL}$ ) containing $0.3 \mathrm{mmol} / \mathrm{L} \mathrm{Cu}(\mathrm{II})$, or $0.3 \mathrm{mmol} / \mathrm{L}$ PFOS. The solution $\mathrm{pH}$ was adjusted to 3-6 using $0.1 \mathrm{M} \mathrm{HNO}_{3}$ or $\mathrm{NaOH}$. The suspensions were rotated continuously for $24 \mathrm{~h}$ at room temperature $\left(20 \pm 1{ }^{\circ} \mathrm{C}\right)$. The $\xi$-potentials were determined following the method described by Pei et al. [32].

\subsection{X-ray absorption measurements and data analyses}

The adsorbed samples were prepared according to the above sorption procedures, where the initial concentration of $\mathrm{Cu}(\mathrm{II})$ is $0.1 \mathrm{mmol} / \mathrm{L}$, and the PFOS to $\mathrm{Cu}(\mathrm{II})$ ratios are 0,1 and 5 , respectively. After the adsorption reached equilibrium, samples were centrifuged to replace the supernatant with fresh adsorbate solution of initial composition. This procedure was repeated three times. The X-ray Absorption Near-Edge Structure (XANES) spectra of $\mathrm{Cu}$ were collected at Beijing Synchrotron Radiation Facility on 4W1B beamline. The conditions of X-ray absorption spectroscopic measurements were described previously [32]. The X-ray absorption spectra at $\mathrm{Cu}$ K-edges were recorded at a wiggler beamline and EXAFS end station of the Beijing Synchrotron Radiation Facility (China) using a homemade $\mathrm{Si}(111)$ double-crystal monochromator. During the experiment, the storage ring was operated at $2.2 \mathrm{GeV}$, with a beam current of approximately $80 \mathrm{~mA}$. To suppress the unwanted high-order harmonics, the parallelism of the two crystals in the monochromator was adjusted to mistune the incident beam by $30 \%$. The incident beam intensities were monitored and recorded using a nitrogen gas-flow ionization chamber. The fluorescence signals were measured using a Lytle-type fluorescence detector (EXAFS Company, Pioche, NV, USA) with filter (EXAFS Materials, Danville, CA, USA). Absorption data were collected in an energy range from 8920 to $9080 \mathrm{eV}$, covering the K-edge absorption of $\mathrm{Cu}$ atoms. Three scans were made and averaged for 
both the adsorbed soil samples and the chemical standards. Processing of XANES data and least-square linear combination fitting (LCF) analyses were carried out using WinXAS program (version 3.1). LCF analyses of the $\mathrm{Cu} \mathrm{K}$-edge XANES spectra was performed in the region between 8960 and $9020 \mathrm{eV}$.

\subsection{Adsorption data fitting}

Adsorption isotherms were fitted using the Dubinin-Ashtakhov [33] and Freundlich models.

Dubinin - Ashtakhov model (DA) : $\log q_{\mathrm{e}}=\log Q_{\mathrm{m}}+(\epsilon / E)^{\mathrm{b}}$

Freundlich model $(\mathrm{FM}): q_{\mathrm{e}}=K_{\mathrm{F}} C_{\mathrm{e}}^{\mathrm{N}}$

The concentration-dependent solid-water distribution ratio, $K_{\mathrm{d}}(\mathrm{L} /$ $\mathrm{kg}$ ), indicating adsorption affinity, was calculated based on the following equation:

$K_{\mathrm{d}}=q_{\mathrm{e}} / C_{\mathrm{e}}=K_{\mathrm{F}} C_{\mathrm{e}}^{\mathrm{N}-1}$

where $C_{\mathrm{e}}$ and $q_{\mathrm{e}}(\mathrm{mmol} / \mathrm{kg})$ are the equilibrium adsorbate concentrations in the aqueous and solid phases; $Q_{\mathrm{m}}(\mathrm{mmol} / \mathrm{kg})$ is the maximum loading capacity; $\varepsilon(\mathrm{kJ} / \mathrm{mol}), \varepsilon=-\mathrm{RT} \ln \left(C_{\mathrm{e}} / C_{\mathrm{s}}\right)$, is the effective adsorption potential; $C_{\mathrm{s}}(\mathrm{mmol} / \mathrm{L})$ is the water solubility of solute; $R$ $\left(8.314 \times 10^{-3} \mathrm{~kJ} / \mathrm{mol} / \mathrm{K}\right)$ is the universal gas constant; and $T(\mathrm{~K})$ is the absolute temperature; $E(\mathrm{~kJ} / \mathrm{mol})$ is the correlating divisor; $b$ is a fitting parameter. The $K_{\mathrm{F}}\left[(\mathrm{mmol} / \mathrm{kg}) /(\mathrm{mmol} / \mathrm{L})^{\mathrm{N}}\right]$ is the Freundlich adsorption coefficient and $N$ (dimensionless) is the isotherm nonlinearity factor.

Freundlich equation-derived thermodynamic irreversible index (TII) was calculated to quantify the degree of desorption irreversibility [34]:

$\mathrm{TII}=1-N_{\mathrm{d}} / N_{\mathrm{a}}$

where $N_{\mathrm{a}}$ and $N_{\mathrm{d}}$ are nonlinear factors for sorption and desorption isotherms, respectively. The TII values lies between 0 and 1 , with 0 indicating a completely reversible system and 1 complete irreversibility.

\subsection{Data analysis}

All statistical analyses were conducted with the software Origin version 7.5. One-way ANOVA was used to assess the significance of the difference between groups, and nonlinear regression analyses were conducted by the least-squares method. Statements of significant differences are based on $P<0.05$.

\section{Results}

\subsection{Characterization of MWCNTs}

Selected structural properties of MWCNTs are listed in Table 1. O-MWCNTs have a larger surface area and pore volumes than PriMWCNTs due to the removal of amorphous carbon and hemispherical caps on the nanotubes. Both Pri-MWCNTs and O-MWCNTs
Table 2

Determination of $\mathrm{Cu}^{2+}$ concentrations in solutions measured by $\mathrm{Cu}-\mathrm{ISE}$ in the absence and presence of PFOS.

\begin{tabular}{lllll}
\hline \multirow{2}{*}{ PFOS to Cu(II) ratios } & \multicolumn{4}{l}{ Percentage of $\mathrm{Cu}^{2+}$ to total $\mathrm{Cu}(\mathrm{II})(\%)^{*}$} \\
\cline { 2 - 5 } & $\mathrm{pH} \mathrm{3}$ & $\mathrm{pH} \mathrm{4}$ & $\mathrm{pH} \mathrm{5.5}$ & $\mathrm{pH} \mathrm{6}$ \\
\hline Control & $98.6(1.7)^{\mathrm{a}}$ & $96.9(1.3)^{\mathrm{a}}$ & $96.9(1.0)^{\mathrm{a}}$ & $97.7(1.0)^{\mathrm{a}}$ \\
$0.5: 1$ & $98.2(1.1)^{\mathrm{a}}$ & $97.1(1.7)^{\mathrm{a}}$ & $96.5(1.7)^{\mathrm{b}}$ & $96.2(1.1)^{\mathrm{a}}$ \\
$1: 1$ & $98.2(1.3)^{\mathrm{a}}$ & $96.9(1.5)^{\mathrm{a}}$ & $96.6(1.2)^{\mathrm{a}}$ & $97.0(1.9)^{\mathrm{a}}$ \\
$5: 1$ & $97.6(1.4)^{\mathrm{a}}$ & $94.8(1.3)^{\mathrm{a}}$ & $95.5(0.7)^{\mathrm{a}}$ & $95.9(0.8)^{\mathrm{a}}$ \\
$10: 1$ & $92.9(1.4)^{\mathrm{b}}$ & $91.9(0.6)^{\mathrm{b}}$ & $90.5(0.7)^{\mathrm{b}}$ & $90.5(0.7)^{\mathrm{b}}$ \\
\hline
\end{tabular}

Means within each column with the same letter are not significantly different at the $5 \%$ level.

have oxygen-containing functional groups. Oxidation introduced more oxygen-containing groups on the outermost surface and defect sites, resulting in the decrease of the point of zero charge (PZC) (Table 1).

\subsection{Effect of PFOS on free copper ion $\left(\mathrm{Cu}^{2+}\right)$ concentration in solution}

Effect of PFOS on $\mathrm{Cu}^{2+}$ concentrations that measured by Cu-ISE are shown in Table 2 . More than $95 \%$ of total $\mathrm{Cu}$ in control solution is $\mathrm{Cu}^{2+}$. The presence of PFOS affected $\mathrm{Cu}^{2+}$ concentration slightly. When the ratios of PFOS to $\mathrm{Cu}$ (II) increased from 0.5 to 5 , the percentages of $\mathrm{Cu}^{2+}$ were equivalent to that of the control. When the ratio of PFOS to $\mathrm{Cu}(\mathrm{II})$ was $10, \mathrm{Cu}^{2+}$ concentrations were $90.5-92.9 \%$ of the total $\mathrm{Cu}$ (II) concentrations in solution.

\subsection{Sorption and desorption of PFOS onto and from MWCNTs as affected by $\mathrm{Cu}(\mathrm{II})$}

Adsorption isotherms of PFOS at pH 5.5 on MWCNTs with or without $\mathrm{Cu}$ (II) are shown in Fig. 2. All the isotherms fitted by both DA and FM well, with the $R^{2}$ values higher than 0.981 and 0.988 for DA and FM respectively (Fig. 2, Table 3 ). The FM parameters suggested that the PFOS sorption isotherms on MWCNTs were all practically nonlinear, with $N$ values ranging from 0.319 to 0.569 . A precise comparison cannot be made according to the $K_{\mathrm{F}}$ values because of their different units as a result of nonlinearity. Therefore, the concentration-dependent sorption coefficient $K_{\mathrm{d}}$ at two selected equilibrium concentrations $\left(C_{\mathrm{e}}\right)(0.05$ and $0.3 \mathrm{mmol} / \mathrm{L})$, and the maximum loading capacity $\left(Q_{m}\right)$ derived from DA model were employed to compare the sorption capacity. The $K_{\mathrm{d}}$ and $Q_{\mathrm{m}}$ values of Pri-MWCNTs were higher than those of O-MWCNTs. The maximum surface coverage of PFOS was calculated by dividing $Q_{m}$ by the calculated monolayer adsorption capacity $\left(Q_{m} / Q_{c a l}\right.$, Table 3$)$. In the absence of $\mathrm{Cu}$ (II), the $Q_{\mathrm{m}} / Q_{\mathrm{cal}}$ values of PFOS for Pri-MWCNTs and O-MWCNTs were 0.643 and 0.348 , respectively.

In the presence of $\mathrm{Cu}(\mathrm{II})$, PFOS adsorption on both Pri-MWCNTs and O-MWCNTs was significantly higher than those in the absence of $\mathrm{Cu}$ (II) (Fig. 2). The larger the $\mathrm{Cu}$ (II) concentrations, the greater the quantity of PFOS adsorbed (Fig. 3). The enhanced factors of O-MWCNTs were larger than that of Pri-MWCNTs. The $\mathrm{Q}_{\mathrm{m}}$ values

Table 1

Selected structural properties of the MWCNTs.

\begin{tabular}{|c|c|c|c|c|c|c|c|c|}
\hline MWCNTs & Out diameter ${ }^{\mathrm{a}}(\mathrm{nm})$ & Inner diameter ${ }^{\mathrm{a}}(\mathrm{nm})$ & Length $(\mu \mathrm{m})$ & Oxygen $^{\mathrm{b}}$ content $(\%)$ & $A_{\text {surf }}{ }^{\mathrm{c}}(\mathrm{m} 2 / \mathrm{g})$ & $V_{\text {meso }}{ }^{\mathrm{c}}\left(\mathrm{cm}^{3} / \mathrm{g}\right)$ & $V_{\text {micro }}{ }^{\mathrm{c}}\left(\mathrm{cm}^{3} / \mathrm{g}\right)$ & PZC \\
\hline Pri-MWCNTs & $10-20$ & $5-10$ & $10-30$ & 1.52 & 149.3 & 0.305 & 0.016 & 4.0 \\
\hline O-MWCNTs & $10-20$ & $5-10$ & $10-30$ & 7.07 & 185.2 & 0.756 & 0.024 & 1.4 \\
\hline
\end{tabular}

a Determined by high-resolution transmission electron microscopy (TEM).

b Oxygen content was analyzed by energy-dispersive X-ray spectroscopy.

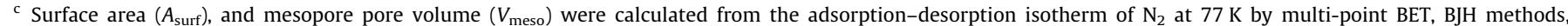
respectively. The micropore volume $\left(V_{\text {micro }}\right)$ was measured by carbon dioxide sorption with Quantachrome instruments v2.2 and calculated with DFT method. 

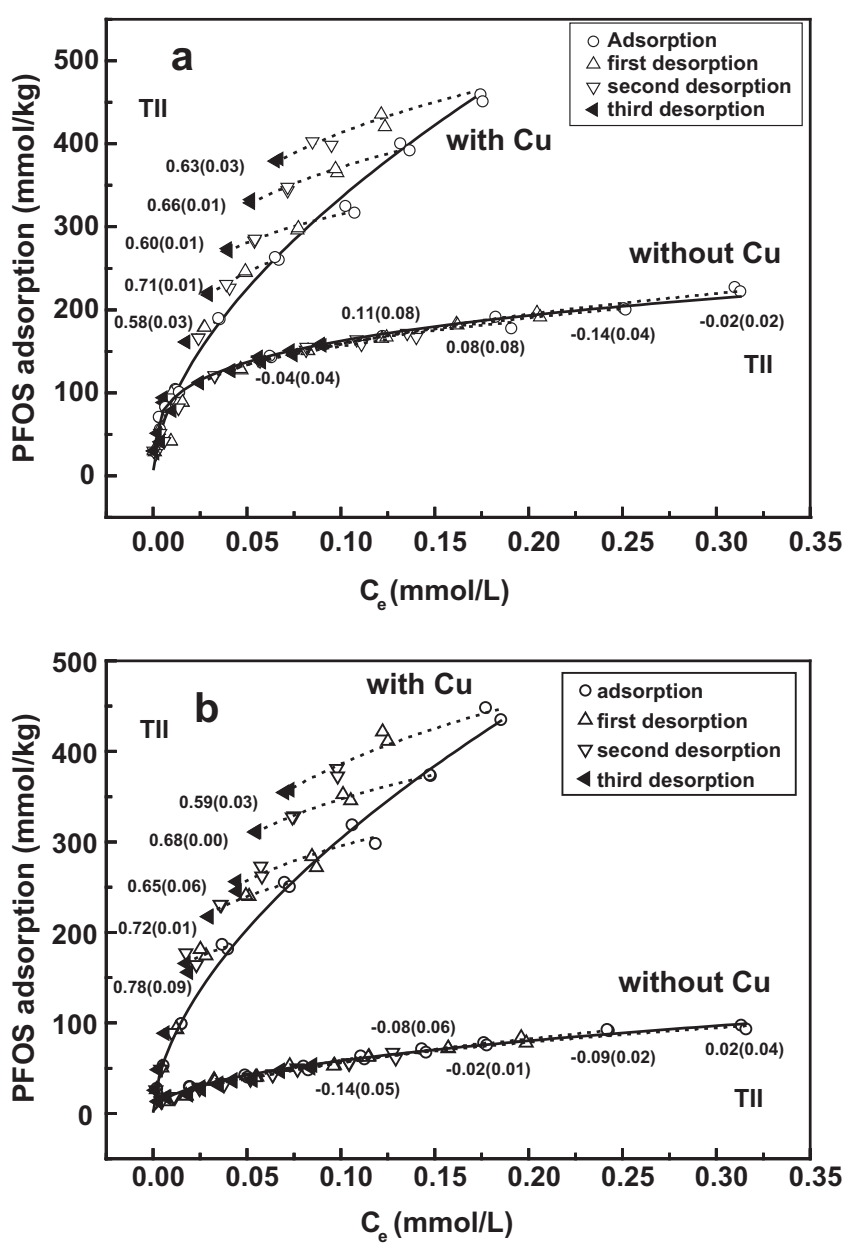

Fig. 2. Effect of $\mathrm{Cu}(\mathrm{II})$ on the sorption and desorption of PFOS from MWCNTs at pH 5.5. (a) Adsorption and desorption isotherms of PFOS on Pri-MWCNTs as effect by $0.26 \mathrm{mmol} / \mathrm{L} \mathrm{Cu}(\mathrm{II})$; (b) Adsorption and desorption isotherms of PFOS on O-

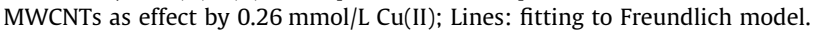

for Pri-MWCNTs and O-MWCNTs in the presence of $\mathrm{Cu}(\mathrm{II})$ were about 5.5 and 6.0 times, respectively, those in the absence of $\mathrm{Cu}(\mathrm{II})$. In the presence of $\mathrm{Cu}(\mathrm{II})$ the $\mathrm{Q}_{\mathrm{m}} / \mathrm{Q}_{\mathrm{cal}}$ values of PFOS for both Pri-MWCNTs and O-MWCNTs were higher than 1.

Desorption of PFOS from Pri-MWCNTs and O-MWCNTs showed no desorption hysteresis in the absence of $\mathrm{Cu}(\mathrm{II})$, whereas a pronounced hysteresis was observed in the presence of $\mathrm{Cu}(\mathrm{II})$ (Fig. 2). The TII was used to quantify the hysteresis. The TII values for PFOS desorption were -0.14 to 0.11 and $0.58-0.78$ for MWCNTs in the absence and presence of $\mathrm{Cu}(\mathrm{II})$, respectively.

\subsection{Sorption and desorption of $\mathrm{Cu}(\mathrm{II})$ onto and from MWCNTs as affected by PFOS}

Adsorption isotherms of $\mathrm{Cu}(\mathrm{II})$ at pH 5.5 on MWCNTs with or without PFOS are shown in Fig. 4. All the isotherms fitted FM well (Fig. 4, Table 4). The parameters derived suggested that the $\mathrm{Cu}(\mathrm{II})$ adsorption on O-MWCNTs was higher than that adsorption on Pri-MWCNTs. In the presence of PFOS, $\mathrm{Cu}(\mathrm{II})$ adsorption increased significantly. For instance, the $\mathrm{K}_{\mathrm{d}}$ value for O-MWCNTs at low $C_{\mathrm{e}}$ $(0.05 \mathrm{mmol} / \mathrm{L})$ in the presence of PFOS was 1.72 times higher than that in the absence of PFOS. The larger the PFOS concentrations, the greater the quantity of $\mathrm{Cu}(\mathrm{II})$ adsorbed (Fig. 5).

Desorption of $\mathrm{Cu}$ (II) from Pri-MWCNTs and O-MWCNTs showed significant desorption hysteresis with and without PFOS (Fig. 4). The TII values in the presence of PFOS were in the range of 0.07-0.43, which was smaller than those in the absence of PFOS (0.38-0.80).

\subsection{Effect of $\mathrm{Cu}(\mathrm{II})$ and PFOS sorption on zeta potential of MWCNTS}

Zeta potentials of Pri-MWCNTs and O-MWCNTs were measured before and after adsorption of $0.3 \mathrm{mmol} / \mathrm{L} \mathrm{Cu}(\mathrm{II})$ or $0.3 \mathrm{mmol} / \mathrm{L}$ PFOS as a function of $\mathrm{pH}$ (Fig. 6). Zeta potentials of Pri-MWCNTs and O-MWCNTs were more negatively charged with increasing solution $\mathrm{pH}$. The sorption of $\mathrm{Cu}(\mathrm{II})$ made the zeta-potentials of MWCNTs surface less negative charged, while the sorption of PFOS made the zeta-potential of Pri-MWCNTs and O-MWCNTs more negative charged.

\subsection{X-ray absorption spectroscopic investigation of coordination environment of $\mathrm{Cu}$}

$\mathrm{Cu}$ K-edge X- absorption near edge structure (XANES) spectral features are very sensitive to molecular coordination. Thus, interpretation of the XANES spectra can be used to determine molecular structure of $\mathrm{Cu}(\mathrm{II})$ adsorbed on MWCNTs.

Fig. 7 shows $\mathrm{Cu}$ K-edge spectra (a) and their first derivatives (b) for $\mathrm{Cu}(\mathrm{II})$ adsorbed on O-MWCNTs, along with two standard compounds $\mathrm{Cu}(\mathrm{OH})_{2}$ precipitation, and $\mathrm{Cu}\left(\mathrm{NO}_{3}\right)_{2}$ in aqueous solutions. The normalized K-edge XANES spectra are very similar. The pre-edge peak in the first derivative spectra is due to the $1 \mathrm{~s}$ to $3 \mathrm{~d}$ electron transition, and is invariant in the $\mathrm{Cu}(\mathrm{II})$ XANES spectra in this study. The obvious two peaks ( $\alpha$ and $\beta$ peaks) in Fig. $7 \mathrm{~b}$ were qualitatively related to the difference between the equatorial and axial $\mathrm{Cu}-\mathrm{O}$ distances in the $\mathrm{CuO6}$ octahedron [35]. The energy separation and intensity of the $\alpha$ and $\beta$ peaks is dependent on molecular

Table 3

Freundlich and Dubinin-Ashtakhov (DA) model isotherm parameters for PFOS with and without $\mathrm{Cu}(\mathrm{II})$.

\begin{tabular}{|c|c|c|c|c|c|c|c|c|c|c|c|c|}
\hline \multirow[t]{3}{*}{ Sorbents } & \multirow[t]{3}{*}{$\mathrm{Cu}$ contents $(\mathrm{mmol} / \mathrm{L})$} & \multicolumn{5}{|l|}{ Freundlich } & \multicolumn{6}{|c|}{ Dubinin-Ashtakhov } \\
\hline & & \multirow[t]{2}{*}{${ }^{\mathrm{a}} \mathrm{K}_{\mathrm{F}}$} & \multirow[t]{2}{*}{$N$} & \multirow[t]{2}{*}{$R^{2}$} & \multicolumn{2}{|l|}{$K_{\mathrm{d}}(\mathrm{L} / \mathrm{kg})$} & \multirow{2}{*}{$\begin{array}{l}Q_{\mathrm{m}} \\
(\mathrm{mmol} / \mathrm{kg})\end{array}$} & \multirow{2}{*}{$\begin{array}{l}E \\
(\mathrm{~kJ} / \mathrm{mol})\end{array}$} & \multirow{2}{*}{$\begin{array}{l}b \\
(\mathrm{mmol} / \mathrm{kg})\end{array}$} & \multirow{2}{*}{$\begin{array}{l}R^{2} \\
(\mathrm{mmol} / \mathrm{kg})\end{array}$} & \multirow{2}{*}{$\begin{array}{l}{ }^{\mathrm{c}} \mathrm{Q}_{\text {cal. }} \\
(\mathrm{mmol} / \mathrm{kg})\end{array}$} & \multirow{2}{*}{$\begin{array}{l}Q_{\mathrm{m}} / Q_{\mathrm{cal}} \\
(\mathrm{mmol} / \mathrm{kg})\end{array}$} \\
\hline & & & & & $\begin{array}{l}{ }^{\mathrm{b}} C_{\mathrm{e}}=0.05 \\
\mathrm{mmol} / \mathrm{L}\end{array}$ & 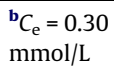 & & & & & & \\
\hline \multirow{2}{*}{ Pri-MWCNTs } & 0 & $319(7)^{d}$ & $0.319(0.010)$ & 0.992 & 2454 & 724 & $232(15)$ & $16.2(0.3)$ & $2.1(0.2)$ & 0.981 & \multirow[t]{2}{*}{361} & 0.643 \\
\hline & 0.26 & $1206(50)$ & $0.560(0.018)$ & 0.995 & 4507 & 2048 & 1266 (159) & $9.8(0.9)$ & $0.9(0.1)$ & 0.997 & & 3.78 \\
\hline \multirow[t]{2}{*}{ O-MWCNTs } & 0 & $169(5)$ & $0.462(0.017)$ & 0.988 & 847 & 323 & $156(22)$ & $12.6(0.6)$ & $1.1(0.1)$ & 0.990 & \multirow[t]{2}{*}{448} & 0.348 \\
\hline & 0.26 & $1129(30)$ & $0.569(0.012)$ & 0.998 & 4107 & 1897 & $932(85)$ & $10.9(0.6)$ & $1.2(0.1)$ & 0.997 & & 2.08 \\
\hline
\end{tabular}

\footnotetext{
a The unit of $K_{\mathrm{F}}$ is $(\mathrm{mmol} / \mathrm{kg}) /(\mathrm{mmol} / \mathrm{L})^{\mathrm{N}} ;{ }^{b} K_{\mathrm{d}}=K_{\mathrm{F}} C_{\mathrm{e}}^{\mathrm{N}-1}$.

b $C_{\mathrm{e}}=0.05 \mathrm{mmol} / \mathrm{L}$ and $C_{\mathrm{e}}=0.3 \mathrm{mmol} / \mathrm{L}$ are the liquid-phase equilibrium concentrations at 0.05 and $0.3 \mathrm{mmol} / \mathrm{L}$, respectively.

c $Q_{\text {cal }}$ is the monolayer adsorption capacity (mmol $/ \mathrm{kg}$ ) calculated by $A_{\text {surf }} /\left(A_{\mathrm{m}} \times N\right) \times 10^{10}$, where $A_{\text {surf }}$ is the CNT surface area (m ${ }^{2} / \mathrm{kg}$ ), $A_{\mathrm{m}}$ is the projecting area of PFOS $\left(\mathrm{cm}^{2}\right)$ estimated by $\pi \times(3 /(4 \pi \times D \times N)) 2 / 3$, where $\mathrm{N}$ is the Avogadro constant, $D$ is the density of PFOS, $1.84 \mathrm{~g} / \mathrm{cm}^{3}$.

d Standard deviation $(\sigma)$.
} 


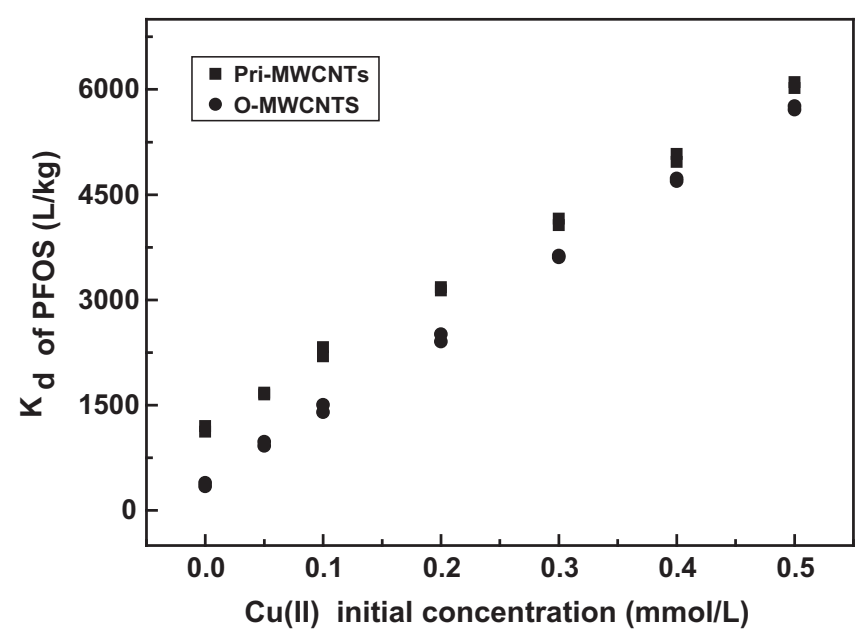

Fig. 3. $K_{d}$ of PFOS $(0.26 \mathrm{mmol} / \mathrm{L})$ as a function of initial $\mathrm{Cu}$ (II) concentrations.

composition and coordination, and can be used to qualitatively assess $\mathrm{Cu}$ speciation on MWCNTs. The first derivatives for $\mathrm{Cu}(\mathrm{II})$ adsorbed on O-MWCNTs were quit difference from that of $\mathrm{Cu}(\mathrm{OH})_{2}$, indicating that the formation of $\mathrm{Cu}(\mathrm{OH})_{2}$ did not account for the adsorption of $\mathrm{Cu}(\mathrm{II})$ on MWCNTs. Compared to that of aqueous $\mathrm{Cu}\left(\mathrm{NO}_{3}\right)_{2}$, the $\alpha$ peak intensity of $\mathrm{Cu}$ adsorbed in the absence of PFOS (Cu-MWCNTs) decreased significantly (Fig. 7b), suggesting that the stronger field water molecules in the tetragonal plane had exchanged with different field organic moieties such as carboxylic and hydroxylic groups. The decreased $\alpha$ peak intensity in $\mathrm{Cu}$ adsorbed on MWCNTs also suggested that O-MWCNTs was sterically hindered due to their three-dimensional structure and that when $\mathrm{Cu}$ approached the surface, $\mathrm{Cu}$ could not be bound in the equatorial plane with the same degree of angular overlap as that of water. These indicated that the adsorbed Cu was present in a disordered geometry of an inner-sphere complex. When the PFOS to $\mathrm{Cu}(\mathrm{II})$ ratio is 1 , the first derivative spectrum is similar to that in the absence of PFOS. Fitting the first derivative spectrum of $\mathrm{Cu}(\mathrm{II})$ adsorbed on O-MWCNTs (PFOS/Cu $=1$ ) using both the aqueous $\mathrm{Cu}\left(\mathrm{NO}_{3}\right)_{2}$ and $\mathrm{Cu}-\mathrm{MWCNTs}$ spectra resulted in $3.6 \% \mathrm{Cu}\left(\mathrm{NO}_{3}\right)_{2}$ and $96.4 \% \mathrm{Cu}-\mathrm{MWCNTs}$, with a residual of $5.5 \%$ (Fig. 8a), which indicated that $\mathrm{Cu}(\mathrm{II})$ adsorbed mainly as an inner-sphere complex when PFOS to Cu ratio is 1 . When the PFOS to $\mathrm{Cu}$ ratio increased from 1 to 5 , the position of the $\alpha$ and $\beta$ peaks for the XANES spectrum match well with the hydrated $\mathrm{Cu}(\mathrm{II})$. Using aqueous $\mathrm{Cu}(\mathrm{II})$ XANES spectrum as a standard to fit that of $\mathrm{Cu}$ (II) adsorbed on MWCNTs (PFOS/Cu=5), the fit residual was $13.4 \%$. Using both the aqueous $\mathrm{Cu}\left(\mathrm{NO}_{3}\right)_{2}$ and $\mathrm{Cu}-\mathrm{MWCNTs}$ spectra resulted in $80.9 \% \mathrm{Cu}\left(\mathrm{NO}_{3}\right)_{2}$ and $29.1 \% \mathrm{Cu}-\mathrm{MWCNTs}$, with an improvement in fit residual of 5.8\% (Fig. 8b), indicating that when
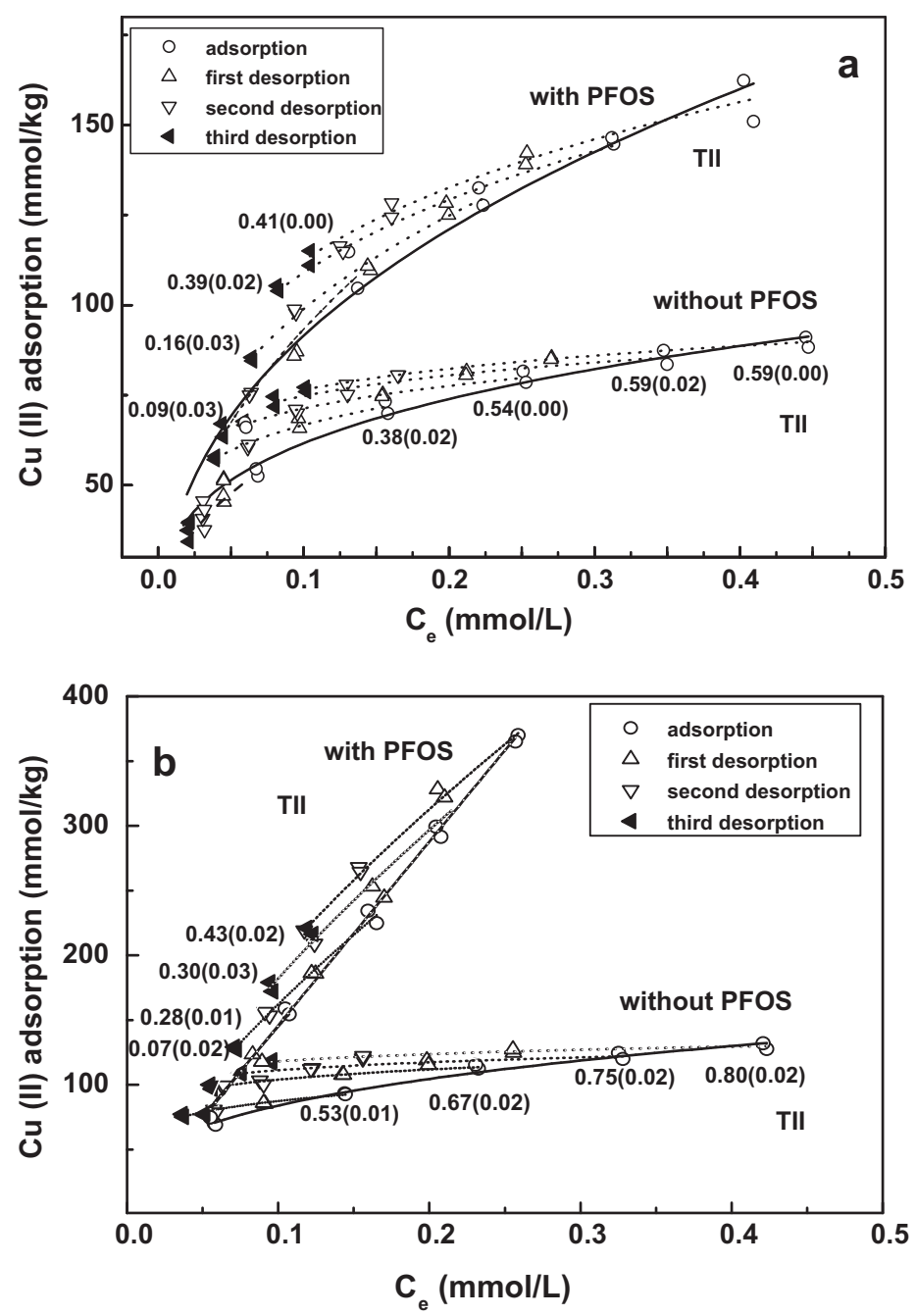

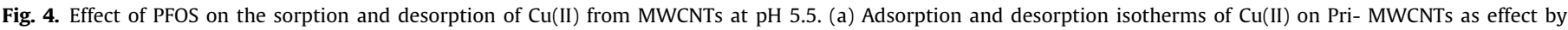
$0.26 \mathrm{mmol} / \mathrm{L}$ PFOS; (b) Adsorption and desorption isotherms of $\mathrm{Cu}(\mathrm{II})$ on O-MWCNTs as effect by $0.26 \mathrm{mmol} / \mathrm{L}$ PFOS. Lines: fitting to Freundlich model. 
Table 4

Freundlich model isotherm parameters for $\mathrm{Cu}(\mathrm{II})$ with and without PFOS.

\begin{tabular}{|c|c|c|c|c|c|c|}
\hline \multirow[t]{2}{*}{ Sorbent } & \multirow[t]{2}{*}{ PFOS mmol/L } & \multirow[t]{2}{*}{$K_{\mathrm{F}}\left(\mathrm{mmol}^{1-N} L^{\mathrm{N}} \mathrm{kg}^{-1}\right)$} & \multirow[t]{2}{*}{$N$} & \multirow[t]{2}{*}{$R^{2}$} & \multicolumn{2}{|l|}{${ }^{\mathrm{a}} K_{\mathrm{d}}(\mathrm{L} / \mathrm{kg})$} \\
\hline & & & & & ${ }^{\mathrm{b}} C_{\mathrm{e}}=0.05 \mathrm{mmol} / \mathrm{L}$ & $C_{\mathrm{e}}=0.5 \mathrm{mmol} / \mathrm{L}$ \\
\hline Pri-MWCNT & 0 & $112.7 \pm 5.2^{c}$ & $0.262 \pm 0.018$ & 0.987 & 1028 & 188 \\
\hline Pri-MWCNT & 0.26 & $231.5 \pm 12.0$ & $0.403 \pm 0.035$ & 0.986 & 1384 & 350 \\
\hline O-MWCNT & 0 & $173.3 \pm 4.4$ & $0.315 \pm 0.016$ & 0.982 & 1348 & 279 \\
\hline O-MWCNT & 0.26 & $1768.8 \pm 120.0$ & $0.929 \pm 0.043$ & 0.994 & 2188 & 1858 \\
\hline
\end{tabular}

${ }^{\mathrm{a}} K_{\mathrm{d}}=K_{\mathrm{F}} C_{\mathrm{e}}^{\mathrm{N}-1}$.

b $C_{\mathrm{e}}=0.05 \mathrm{mmol} / \mathrm{L}$ and $C_{\mathrm{e}}=0.05 \mathrm{mmol} / \mathrm{L}$ are the liquid-phase equilibrium concentration at 0.05 and $0.5 \mathrm{mmol} / \mathrm{L}$, respectively.

c Standard deviation $(\sigma)$.

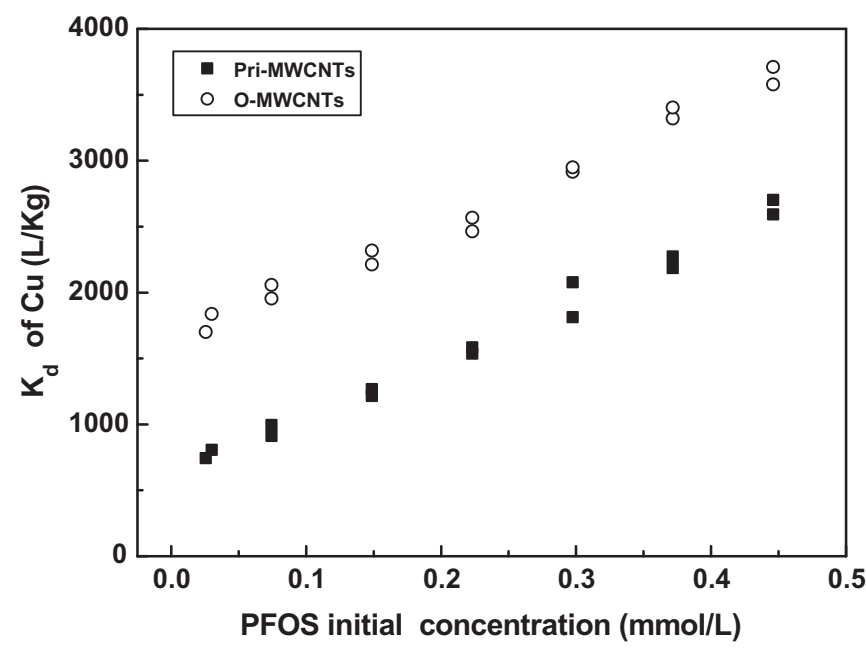

Fig. 5. $K_{\mathrm{d}}$ of $\mathrm{Cu}$ (II) $(0.26 \mathrm{mmol} / \mathrm{L})$ as a function of initial PFOS concentrations.

PFOS to $\mathrm{Cu}(\mathrm{II})$ ratio is $5, \mathrm{Cu}(\mathrm{II})$ adsorbed mainly as out-sphere complex. Thus, we deduced that with the PFOS to $\mathrm{Cu}$ ratio increasing, the portion of $\mathrm{Cu}(\mathrm{II})$ adsorbed as an inner-sphere complex decreased, while those adsorbed as an out-sphere complex increased.

\section{Discussion}

\subsection{Possibility of Cu-PFOS complex formation in solution}

PFOS is an organic acid with the $\mathrm{PK}_{\mathrm{a}}$ of -3.27 . Complex formation between divalent cations $\left(\mathrm{Ca}^{2+}\right.$ and $\mathrm{Mg}^{2+}$ ) and PFOS in solution was proposed [16]. However, no apparent formation constant between PFOS and $\mathrm{Cu}$ (II) was found so far, limiting the performance of PFOS and $\mathrm{Cu}$ (II) chemical speciation calculation using computer programs. In this study, ISE was used to measure the concentrations of $\mathrm{Cu}^{2+}$ in order to explore the possibility of Cu-PFOS complex formation in solution at different $\mathrm{pH}$. The results showed that the concentration of $\mathrm{Cu}^{2+}$ only decreased when PFOS to $\mathrm{Cu}$ (II) ratio was 10, suggesting that the formation of complexes between PFOS and $\mathrm{Cu}(\mathrm{II})$ in solution is very weak.

\subsection{Sorption and desorption of PFOS as affected by $\mathrm{Cu}(\mathrm{II})$}

It is suggested that hydrophobic and electrostatic interactions were involved in the sorption of PFOS on sediment [13], activated sludge [36], MWCNTs [31] and granular active carbon [8]. In this study, in the absence of $\mathrm{Cu}(\mathrm{II})$, the maximum surface coverage of PFOS were $64.3 \%$ and $34.8 \%$ for Pri-MWCNTs and O-MWCNTs, respectively (Table 3 ), indicating that a fraction of surface sites of
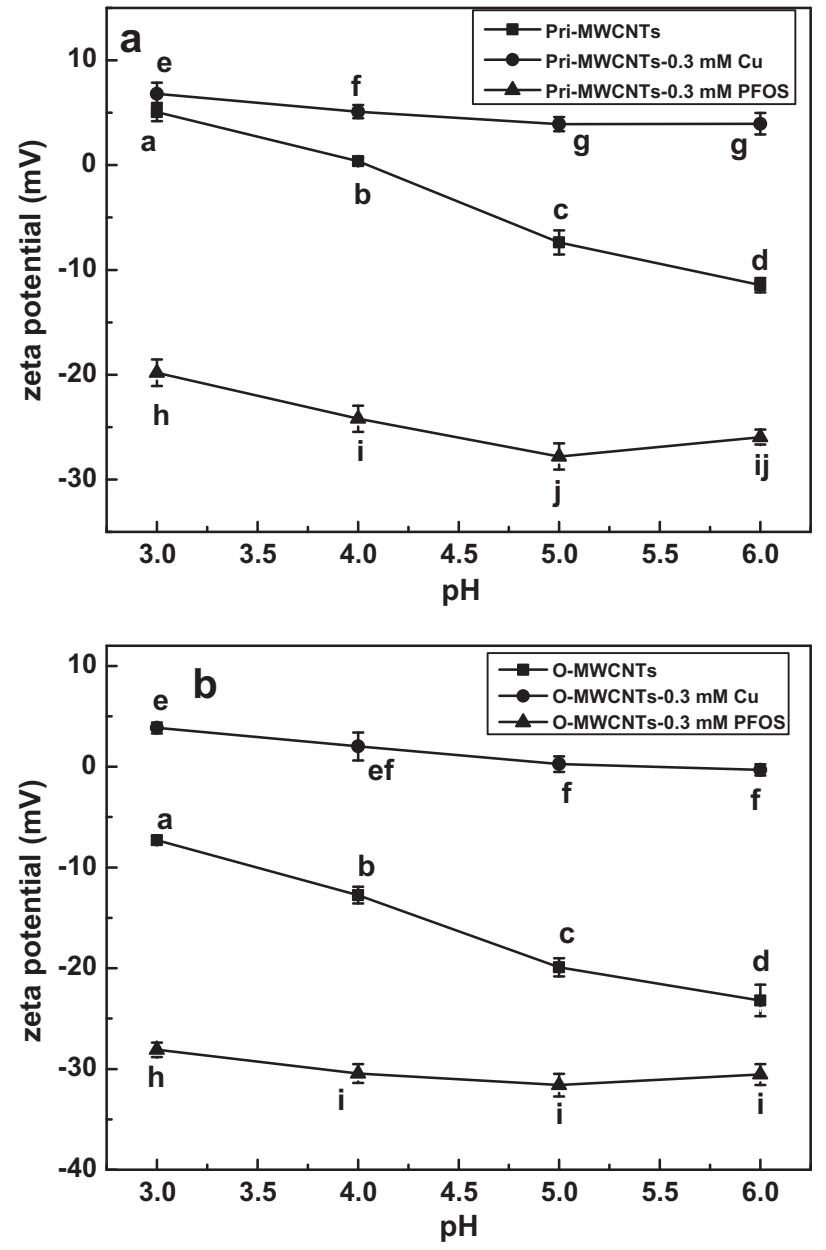

Fig. 6. Zeta potential as a function of pH for Pri-MWCNTs (a) and O-MWCNTs (b) without Cu or PFOS (ם), with $0.3 \mathrm{mmol} / \mathrm{L} \mathrm{Cu}(\mathrm{II})(\bullet), 0.3 \mathrm{mmol} / \mathrm{L} \operatorname{PFOS}(\boldsymbol{\Delta})$.

Pri-MWCNTs and O-MWCNTs cannot be occupied by PFOS, and the accessible surface sites of Pri-MWCNTs was larger than those of O-MWCNTs. Compared with Pri-MWCNTs, the O-MWCNTs are more hydrophilic and less surface area is accessible to PFOS because the water adsorbed on MWCNTs surface (through H bonding of oxygen), which blocks PFOS approach [37]. Moreover, zeta potential analysis showed that the surface charges of O-MWCNTs are more negative than those of Pri-MWCNTs at pH 5.5 (Fig. 6). Thus compared with that of Pri-MWCNTs, much electrostatic repulsion between the anionic PFOS and deprotonated hydroxylic and carboxylic groups of O-MWNTs is expected to weak the sorption of PFOS. Li et al. also reported that the adsorption of ionizable organic contaminants decreased with oxygen contents of MWCNTs increasing [31]. 

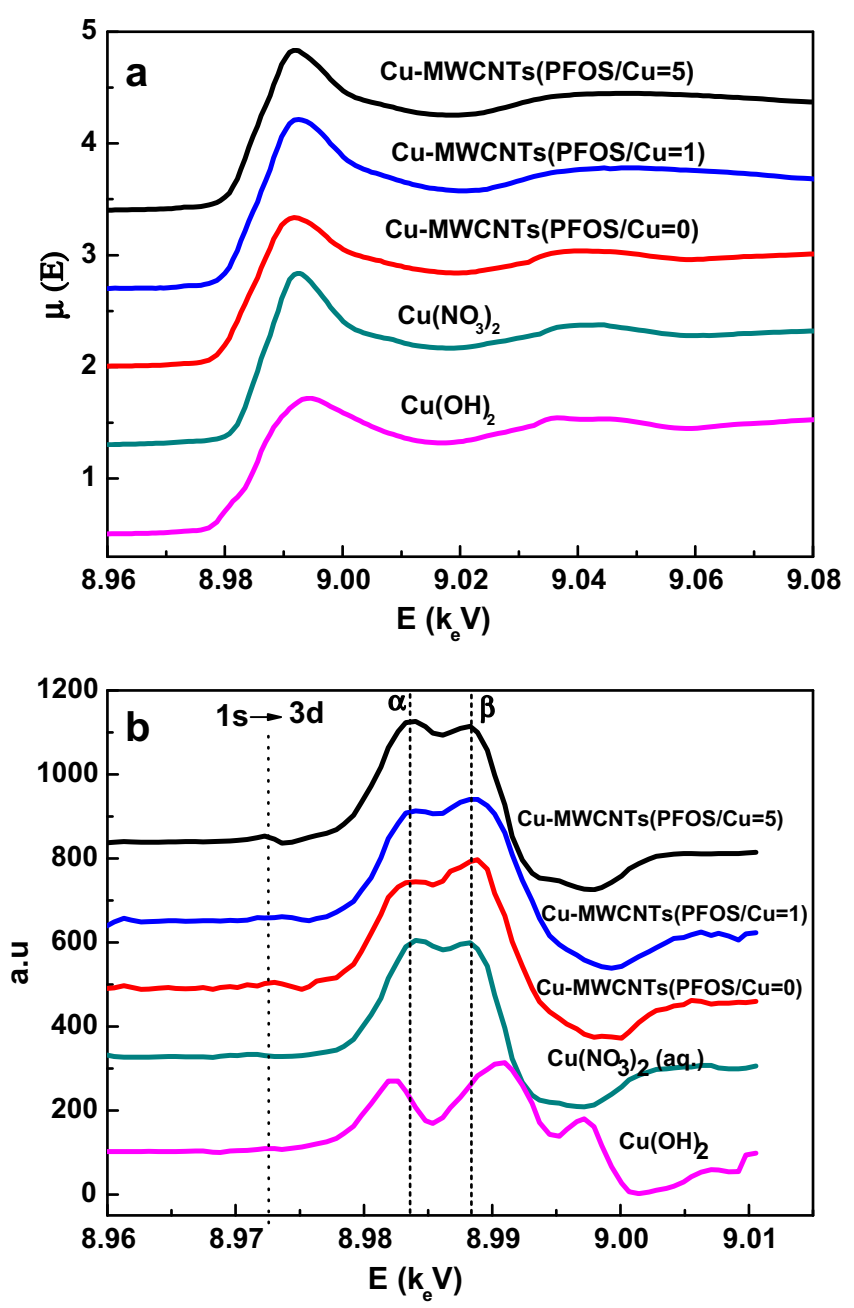

Fig. 7. Normalized XANES spectra (pre- and near-edge region) of $\mathrm{Cu}(\mathrm{II})-\mathrm{O}-\mathrm{MWCNTS}$ (a), and the corresponding first derivatives (b).

In the presence of $\mathrm{Cu}(\mathrm{II})$, adsorption of PFOS on MWCNTs increased obviously, and the maximum surface coverage for PriMWCNTs and O-MWCNTs were higher than 1 (Table 3), indicating that the presence of $\mathrm{Cu}(\mathrm{II})$ not only enhanced the PFOS accessibility to MWCNTs, but also provided extra sorption sites. Various mechanisms were postulated to be responsible for the increases of anionic chemical sorption in the presence of divalent cation, including salt-out effect, which decreased the solubility of PFOS [38], and the neutralization of the negative charge on the sorbent surface [13], which reduced the electrostatic repulsion between the negative charged sorbent surface and the anionic PFOS. Moreover, $\mathrm{Cu}$ (II) can adsorb onto MWCNT surface sites, resulting in positive $\mathrm{Cu}$ sites to which negatively charged PFOS will be attached due to electrostatic interactions. $\mathrm{Cu}$ (II) could form a bridge between the anionic MWCNTs functional groups (e.g., carboxyl and hydroxyl groups) and the anionic PFOS could adsorb with Cu-bridging sorption mechanism [12]. Results of zeta potential analysis demonstrated the positive surface sites at $\mathrm{pH} 5.5$ in the presence of $0.3 \mathrm{mmol} \mathrm{L}^{-1}$ $\mathrm{Cu}$ (II) (Fig. 6). The adsorption above a simply monolayer adsorption may due to that adsorbed molecules are oblique to the surface of MWCNTs with an angle [39]. In this case, the $-\mathrm{SO}_{3}^{-}$group of PFOS could be responsible for this oblique attachment because these groups can be attracted by the positive surface sites.

Sannino et al. postulated that there are two types of mechanisms for the adsorption of anionic organic chemicals: a physical and a chemical adsorption [40]. Physically adsorbed anionic organic chemicals would be easily removed, whereas those via cationbridge would be more strongly retained, which may be in charge of irreversible desorption. Yang and Xing suggested that the capillary condensation in mesopores or macropores, rearrangement of the bundles or aggregates of MWCNTs, and the formation of covalent bound between oxygen-containing functional groups of MWCNTs and oxygen- or nitrogen-containing functional groups of the organic chemicals are responsible for the desorption hysteresis of organic pollutants from MWCNTs [17]. In this study, no hysteresis was found for PFOS desorption in the absence of $\mathrm{Cu}(\mathrm{II})$, indicating that adsorption of PFOS on MWCNTs without $\mathrm{Cu}(\mathrm{II})$ are mainly physical adsorption. In the presence of $\mathrm{Cu}$ (II), PFOS may adsorb on MWCNTs via Cu-bridge, which would be more strongly retained on the MWCNT surface. Alternatively, rearrangement of the bundles or aggregates of MWCNTs alteration of adsorbent structure or reorganization after $\mathrm{Cu}$ (II) adsorption may be another reason to be responsible for the desorption hysteresis in the presence of $\mathrm{Cu}(\mathrm{II})$, because $\mathrm{Cu}(\mathrm{II})$ could act by cross-linking functional groups on adjacent tubes, creating a more tightly knit bundle [19].

\subsection{Sorption and desorption of $\mathrm{Cu}(\mathrm{II})$ as affected by PFOS}

The mechanisms of heavy metal ion adsorption on MWCNTs include physical adsorption, electrostatic attraction, precipitation and chemical interaction between the heavy metal ions and the surface functional groups of CNTs. Among these, chemical interaction between the heavy metal ions and the surface functional groups of CNTs is the major adsorption mechanism [18]. In this study, the desorption hysteresis of $\mathrm{Cu}$ (II) was found for both O-MWCNTs and Pri-MWCNTs, indicating the chemical interaction between $\mathrm{Cu}(\mathrm{II})$ and the functional groups on O-MWCNTs and PriMWCNTs. The Freundlich parameter $K_{d}$ values of O-MWCNTs was about 1.5 times that of MWCNTs (Table 4), which was attributed to the higher amount of $O$ contents on O-MWCNTs surface (Table 1 ). $\mathrm{Wu}[30]$ reported that the adsorption of $\mathrm{Cu}^{2+}$ on as-produced CNTs and $\mathrm{HNO}_{3}$-modified CNTs is a chemically specific reaction. The maximum sorption capacity of $\mathrm{Cu}$ (II) on $\mathrm{HNO}_{3}$-modified CNTs was about 1.68 times that of as-produced CNTs. Chen et al. [28] suggested that $\mathrm{Cu}(\mathrm{II})$ was adsorbed on MWCNTs through formation of an inner-sphere complex in which the water molecules were partly displaced by the carboxylic and hydroxylic groups of MWCNTs. In this study, the formation of strong inner-sphere complexes between $\mathrm{Cu}(\mathrm{II})$ and oxygen containing functional groups of O-MWCNTs in the absence of PFOS was also demonstrated by Xray absorption spectroscopy (Fig. 7). This inner-sphere complexes were responsible for the desorption hysteresis of $\mathrm{Cu}(\mathrm{II})$ from MWCNTs (Fig. 4). In the presence of PFOS, Cu(II) adsorption on MWCNTs significantly increased, and the desorption hysteresis index decreased. The changes of adsorption-desorption behavior of $\mathrm{Cu}$ (II) indicated the shift of sorption mechanisms. PFOS mainly adsorbed on the hydrophobic sites of MWCNTs [31], leading to the lower zeta potential of these sites (Fig. 6). The reason for enhanced $\mathrm{Cu}$ (II) sorption in the presence of PFOS was possibly due to $\mathrm{Cu}$ (II) adsorption not only through the complexation with oxygen containing functional groups of MWCNTs, but also through electrostatic interaction with the adsorbed PFOS, that is, through formation of outer-sphere complex via PFOS bridge. With PFOS concentration increasing, out-sphere complex was the main adsorption mechanism, as verified by X-ray spectroscopy when PFOS to $\mathrm{Cu}$ (II) ratio was 5 (Fig. 8).

The results from this study showed that PFOS and $\mathrm{Cu}(\mathrm{II})$ exhibited different adsorption and desorption behavior in single- and bi-solute systems, though the formation of complex between PFOS and $\mathrm{Cu}(\mathrm{II})$ in solution is very weak. The coexistence of PFOS and $\mathrm{Cu}$ (II) could increase their adsorption on MWCNTs significantly, 

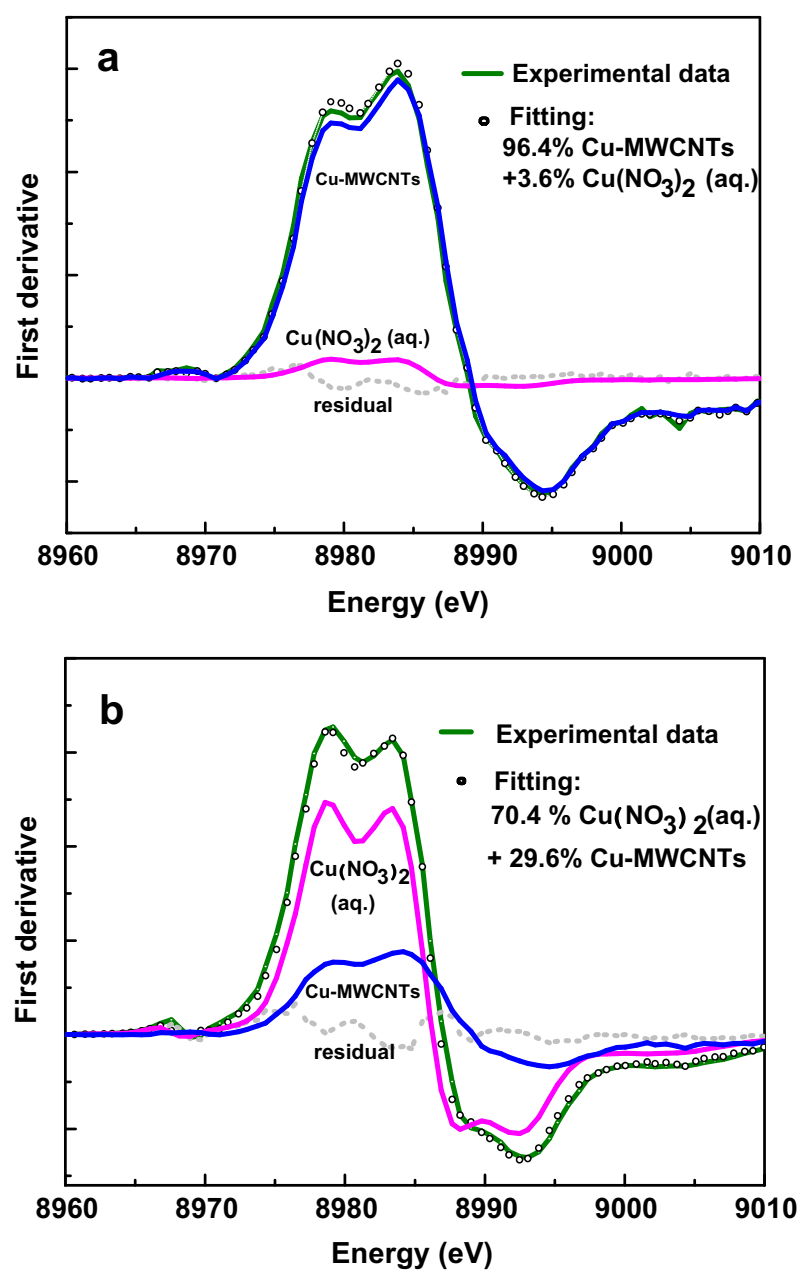

Fig. 8. Copper K-edge first derivative XANES spectrum of $\mathrm{Cu}$ adsorbed on the $\mathrm{O}$ MWCNTs at PFOS to Cu ratios of 1:1(a) and 5:1 (b) and the LCF results (open circles). The weighted components and corresponding residual are displayed in the figure.

thus enhancing the elimination of PFOS and $\mathrm{Cu}(\mathrm{II})$ from wastewater using MWCNTs. In bi-solute system, desorption hysteresis factors of PFOS were larger, while hysteresis factors of $\mathrm{Cu}(\mathrm{II})$ were smaller than those in single-solute system. The different sorption and desorption of PFOS and $\mathrm{Cu}(\mathrm{II})$ between single-and bi-solute system could be attributed to the $\mathrm{Cu}(\mathrm{II})$ adsorption via the PFOS bridge, and the PFOS adsorption via the $\mathrm{Cu}(\mathrm{II})$ bridge.

\section{Conclusions}

In view of the foregoing study, the coexistence of PFOS and $\mathrm{Cu}$ (II) enhanced their adsorption onto Pri-MWCNTs and O-MWCNTs, which indicated that the removing efficiency of PFOS and $\mathrm{Cu}(\mathrm{II})$ by MWCNTs from wastewater would be enhanced. Desorption of PFOS showed no hysteresis without $\mathrm{Cu}(\mathrm{II})$, while pronounced hysteresis with $\mathrm{Cu}(\mathrm{II})$. Desorption of $\mathrm{Cu}(\mathrm{II})$ without PFOS showed significant desorption hysteresis, while the desorption hysteresis factors decreased with PFOS. The difference of sorption and desorption behavior of PFOS and $\mathrm{Cu}(\mathrm{II})$ between those in single-solute and bi-solute systems may be attributed to the sorption of PFOS via a $\mathrm{Cu}(\mathrm{II})$ bridge, while the sorption of $\mathrm{Cu}(\mathrm{II})$ via a PFOS bridge. Results obtained from X-ray absorption spectroscopy verified the formation of inner-sphere complexes between $\mathrm{Cu}(\mathrm{II})$ and functional groups of MWCNTs without PFOS, while out-sphere complexes with large amount of PFOS.

\section{Acknowledgements}

This work was funded by the National Basic Research Program of China (Project 2011CB936001) and the National Natural Science Foundation of China (Grant Nos. 41071308, 21007057). We gratefully acknowledge Dr. Lirong Zheng and Prof. Jing Zhang (Beijing Synchrotron Radiation Laboratory, Institute of High Energy Physics, Chinese Academy of Sciences) for technical assistance during the XAS experiments.

\section{References}

[1] C.L. Tseng, L.L. Liu, C.M. Chen, W.H. Ding, Analysis of perfluorooctanesulfonate and related fluorochemicals in water and biological tissue samples by liquid chromatography-ion trap mass spectrometry, J. Chromatogr. A 1105 (2006) 119-126.

[2] J.P. Giesy, K. Kannan, Mass budget of perfluorooctane surfactants in the environment, Environ. Sci. Technol. 36 (2002) 147-152.

[3] A.M. Becker, S. Gerstmann, H. Frank, Perfluorooctane surfactants in waste waters, the major source of river pollution, Chemosphere 72 (2008) 115121.

[4] R. Guo, W.J. Sim, E.S. Lee, J.H. Lee, Evaluation of the fate of perfluoroalkyl wastewater treatment plants, Water Res. 44 (2010) 3476-3486.

[5] E. Sinclair, K. Kannan, Mass loading and fate of perfluoroalkyl surfactants in wastewater treatment plants, Environ. Sci. Technol. 40 (2006) 1408-1414.

[6] B. Boulanger, J.D. Vargo, J.L. Schnoor, K.C. Hombuckle, Evaluation of perfluorooctane surfactants in a wastewater treatment system and in a commercial surface protection product, Environ. Sci. Technol. 39 (2005) 55245530.

[7] S. Senevirathna, S. Tanaka, S. Fujii, C. Kunacheva, H. Harada, B. Ariyadasa, B.R. Shivakoti, Adsorption of perfluorooctane sulfonate (n-PFOS) onto non ionexchange polymers and granular activated carbon: batch and column test, Desalination 260 (2010) 29-33.

[8] Q. Yu, R. Zhang, S. Deng, J. Huang, G. Yu, Sorption of perfluorooctane sulfonate and perfluorooctanoate on activated carbons and resin: kinetic and isotherm study, Water Res. 43 (2009) 1150-1158.

[9] Q. Yu, S.B. Deng, G. Yu, Selective removal of perfluorooctane sulfonate from aqueous solution using chitosan-based molecularly imprinted polymer adsorbents, Water Res. 42 (2008) 3089-3097.

[10] S. Babel, T.A. Kurniawan, Low-cost adsorbents for heavy metals uptake from contaminated water: a review, J. Hazard. Mater. 97 (2003) 219-243.

[11] K. Kadirvelu, K. Thamaraiselvi, C. Namasivayam, Removal of heavy metal from industrial wastewaters by adsorption onto activated carbon prepared from an agricultural solid waste, Bioresour. Technol. 76 (2001) 63-65.

[12] S. Hyun, L. Lee, Quantifying the contribution of different sorption mechanisms for 2,4-dichlorophenoxyacetic acid sorption by several variable-charge soils, Environ. Sci. Technol. 39 (2005) 2522-2528.

[13] C.P. Higgins, R.G. Luthy, Sorption of perfluorinated surfactants on sediments, Environ. Sci. Technol. 40 (2006) 7251-7256.

[14] H. Chen, S. Chen, X. Quan, Y.Z. Zhao, H.M. Zhao, Sorption of perfluorooctane sulfonate (PFOS) on oil and oil-derived black carbon: influence of solution $\mathrm{pH}$ and $\left[\mathrm{Ca}^{2+}\right]$, Chemosphere 77 (2009) 1406-1411.

[15] C.Y. Tang, Q.S. Fu, D.W. Gao, C.S. Criddle, J.O. Leckie, Effect of solution chemistry on the adsorption of perfluorooctane sulfonate onto mineral surfaces, Water Res. 44 (2010) 2654-2662.

[16] F. Wang, K. Shih, Adsorption of perfluorooctanesulfonate (PFOS) and perfluorooctanoate (PFOA) on alumina: influence of solution $\mathrm{pH}$ and cations, Water Res. 45 (2011) 2925-2930.

[17] K. Yang, B.S. Xing, Adsorption of organic compounds by carbon nanomaterials in aqueous phase: polanyi theory and its application, Chem. Rev. 110 (2010) 5989-6008.

[18] X.M. Ren, C.L. Chen, M. Nagatsu, X.K. Wang, Carbon nanotubes as adsorbents in environmental pollution management: a review, Chem. Eng. J. 170 (2010) 395-410.

[19] C.L. Chen, X.K. Wang, M. Nagatsu, Europium adsorption on multiwall carbon nanotube/iron oxide magnetic composite in the presence of polyacrylic acid, Environ. Sci. Technol. 43 (2009) 2362-2367.

[20] S.B. Yang, J. Hu, C.L. Chen, D.D. Shao, X.K. Wang, Mutual effects of $\mathrm{Pb}(\mathrm{II})$ and humic acid adsorption on multiwalled carbon nanotubes/polyacrylamide composites from aqueous solutions, Environ. Sci. Technol. 45 (2011) 36213627.

[21] J. Hu, D.D. Shao, C.L. Chen, G.D. Sheng, J.X. Li, X.K. Wang, M. Nagatsu, Plasmainduced grafting of cyclodextrin onto multiwall carbon nanotube/iron oxides for adsorbent application, J. Phys. Chem. B 114 (2010) 6779-6785.

[22] J.M. Pan, X.H. Zou, X. Wang, W. Guan, C.X. Li, Y.S. Yan, X.Y. Wu, Adsorptive removal of 2,4-didichlorophenol and 2,6-didichlorophenol from aqueous solution by $\beta$-cyclodextrin/attapulgite composites: equilibrium, kinetics and thermodynamics, Chem. Eng. J. 166 (2011) 40-48.

[23] V.K. Gupta, S. Agarwal, T.A. Saleh, Chromium removal by combining the magnetic properties of iron oxide with adsorption properties of carbon nanotubes, Water Res. 45 (2011) 2207-2212. 
[24] T.A. Saleh, V.K. Gupta, Photo-catalyzed degradation of hazardous dye methyl orange by use of a composite catalyst consisting of multi-walled carbon nanotubes and titanium dioxide, J. Colloid Interface Sci. 371 (2012) 101106.

[25] T.A. Saleh, The influence of treatment temperature on the acidity of MWCNT oxidized by $\mathrm{HNO}_{3}$ or a mixture of $\mathrm{HNO}_{3} / \mathrm{H}_{2} \mathrm{SO}_{4}$, Appl. Surf. Sci. 257 (2011) 7746-7751.

[26] T.A. Saleh, M.A. Gondal, Q.A. Drmosh, Preparation of a MWCNT/ZnO nanocomposite and its photocatalytic activity for the removal of cyanide from water using a laser, Nanotechnology 21 (2010) 495705-495712.

[27] V.K. Gupta, S. Agarwal, T.A. Saleh, Synthesis and characterization of aluminacoated carbon nanotubes and their application for lead removal, J. Hazard. Mater. 185 (2011) 17-23.

[28] G.C. Chen, X.Q. Shan, Y.S. Wang, Z.G. Pei, X.E. Shen, B. Wen, G. Owen, Effects of copper, lead, and cadmium on the sorption and desorption of atrazine onto and from carbon nanotubes, Environ. Sci. Technol. 42 (2008) 8297-8302

[29] G.C. Chen, X.Q. Shan, Y.S. Wang, B. Wen, Z.G. Pei, Y.N. Xie, T. Liu, J.J. Pignatello, Adsorption of 2,4,6-trichlorophenol by multi-walled carbon nanotubes as affected by $\mathrm{Cu}(\mathrm{II})$, Water Res. 43 (2009) 2409-2418.

[30] C.H. Wu, Studies of the equilibrium and thermodynamics of the adsorption of $\mathrm{Cu}^{2+}$ onto as-produced and modified carbon nanotubes, J. Colloid Interface Sci. 311 (2007) 338-346.

[31] X.N. Li, H.M. Zhao, X. Quan, S. Chen, Y.B. Zhang, H.T. Yu, Adsorption of ionizable organic contaminants on multi-walled carbon nanotubes with different oxygen contents, J. Hazard. Mater. 186 (2011) 407-415.
[32] Z.G. Pei, X.O. Shan, S.Z. Zhang, J.J. Kong, B. Wen, J. Zhang, L.R. Zheng, Y.N. Xie, K. Janssens, Insight to ternary complexes of co-adsorption of norfloxacin and $\mathrm{Cu}$ (II) onto montmorillonite and different $\mathrm{pH}$ using EXAFS, J. Hazard. Mater. 186 (2011) 842-848.

[33] M.M. Dubinin, V.A. Astakhov, Development of concepts of volume filling of micropores in adsorption of gases and vapors by microporous adsorbents, Russ. Chem. Bull. 20 (1971) 3-7.

[34] M. Sander, Y. Lu, J.J. Pignatello, A thermodynamically based method to quantify true sorption hysteresis, J. Environ. Qual. 34 (2005) 1063-1072.

[35] A.I. Frenkel, G.V. Korshin, A.L. Ankudinov, XANES study of $\mathrm{Cu}^{2+}$ - binding sites in aquatic humic substances, Environ. Sci. Technol. 34 (2000) 2138-2142.

[36] Q. Zhou, S.B. Deng, Q.Y. Zhang, Q. Fan, J. Huang, G. Yu, Sorption of perfluorooctane sulfonate and perfluorooctanoate on activated sludge, Chemosphere 81 (2010) 453-458.

[37] B. Pan, B.S. Xing, Adsorption mechanisms of organic chemicals on carbon nanotubes, Environ. Sci. Technol. 42 (2008) 9005-9013.

[38] C. You, C.X. Jia, G. Pan, Effect of salinity and sediment characteristics on the sorption and desorption of perfluorooctane sulfonate at sediment-water interface, Environ. Pollut. 158 (2010) 1343-1347.

[39] K. Yang, W.H. Wu, Q.F. Jing, W. Jiang, B.S. Xing, Competitive adsorption of naphthalene with 2,4-dichlorophenol and 4-chloroaniline on multiwalled carbon nanotubes, Environ. Sci. Technol. 44 (2010) 3021-3027.

[40] F. Sannino, A. Violante, L. Gianfreda, Adsorption desorption of 2,4-D by hydroxy aluminium montmorillonite complexes, Pestic. Sci. 51 (1997) 429435. 